\title{
Pretreatment Neutrophil-to-Lymphocyte Ratio and
} Platelet-to-Lymphocyte Ratio as Prognostic Factors and Reference Markers of Treatment Options for Locally Advanced Squamous Cell Carcinoma Located in the Middle and Upper Esophagus

This article was published in the following Dove Press journal: Cancer Management and Research

\author{
Chen Wang ${ }^{1} *$ \\ Jiaqi Tong ${ }^{2, *}$ \\ Mengqiu Tang ${ }^{3}$ \\ Yunyun $\mathrm{Lu}^{3}$ \\ Gaofeng Liang ${ }^{4}$ \\ Zhanchun Zhang ${ }^{3}$ \\ Tian Chen $^{3}$ \\ 'Department of Gastroenterology, \\ Ningbo Medical Center, Lihuili Hospital, \\ Ningbo, People's Republic of China; \\ ${ }^{2}$ Department of Hematology, Ningbo \\ Medical Center, Lihuili Hospital, Ningbo, \\ People's Republic of China; ${ }^{3}$ Department \\ of Radiation Oncology, Ningbo Medical \\ Center, Lihuili Hospital, Ningbo, People's \\ Republic of China; ${ }^{4}$ Department of \\ Thoracic Surgery, Ningbo Medical \\ Center, Lihuili Hospital, Ningbo, People's \\ Republic of China
}

*These authors contributed equally to this work
Correspondence: Tian Chen Email Ihldbyyct@I26.com
Background: Various inflammatory biomarkers, such as the neutrophil-to-lymphocyte ratio (NLR) and platelet-to-lymphocyte ratio (PLR), have been well authenticated to predict clinical outcomes in numerous types of cancer. The optimal treatment for patients with locally advanced esophageal squamous cell carcinoma (ESCC) located in the middle or upper region is still inconclusive. The aim of the study was to examine pretreatment NLR and PLR to select from radical surgery or definitive chemoradiotherapy (dCRT) for these patients. The linkage between pretreatment NLR/PLR and prognosis was also analyzed.

Methods: NLR and PLR were calculated in 113 locally advanced ESCC located in the middle or upper esophagus of patients who underwent radical surgery or dCRT between January 2014 and December 2019. A receiver operating characteristic curve was plotted to select the best cut-off value of NLR and PLR for predicting survival. A survival curve was plotted using the Kaplan-Meier method. Univariate and multivariate Cox regression analyses were applied to assess predictors for survival.

Results: NLR and PLR were associated with the extent of lymph node metastasis (NLR: $P=$ 0.045; PLR: $P=0.002)$. Additionally, high PLR and recurrence with distant organ metastasis were closely related $(P=0.014)$, and NLR was related to the tumor stage $(P=0.043)$. The results of the multivariate analysis revealed that $\operatorname{NLR}(>2.07)$ and PLR $(>183.06)$ were independently associated with poor prognosis. It is noteworthy that surgery was associated with a superior OS compared with dCRT in the low NLR population $(P=0.045)$.

Conclusion: Low pretreatment NLR patients are fit to undergo radical surgery with a substantial therapeutic benefit. Pretreatment NLR and PLR are independent predictors for patients with locally advanced ESCC located in the middle and upper esophagus who underwent radical surgery or dCRT.

Keywords: neutrophil-to-lymphocyte ratio, platelet-to-lymphocyte ratio, esophageal squamous cell carcinoma, definitive chemoradiotherapy, surgery, prognostic factor, reference marker

\section{Background}

Esophageal cancer is the eighth most common malignancy and the sixth leading cause of cancer-related deaths worldwide. ${ }^{1,2}$ China is the highest-risk region, where esophageal squamous cell carcinoma (ESCC) is most prevalent, with approximately 
$90 \%$ of all histological sub-types compared with developed nations. ${ }^{3}$ In contrast to lower esophageal cancer, middle and upper esophageal cancers are more aggressive and the stages at diagnosis are commonly locally advanced. $^{4}$

The landmark Chemoradiotherapy for Esophageal Cancer Followed by Surgery Study (CROSS) trial has become preferred in locally advanced esophageal cancer. However, the patient population in the CROSS trial had cancers mainly located in the lower esophagus and accounted for only $24 \%$ of the patients with ESCC. ${ }^{5}$ Moreover, a meta-analysis suggested chemoradiotherapy plus surgery had no additional benefit compared with chemoradiation alone in $\mathrm{T} 3 / 4$ or $\mathrm{N}+$ thoracic esophageal cancer, and may enhance postoperative mortality. ${ }^{6}$ Therefore, radical surgery or definitive chemoradiotherapy (dCRT) has been adopted for the treatment of locally advanced ESCC located in the middle and upper esophagus and has become the standard modality recommended by most scholars. ${ }^{7-10}$ Additionally, with the development of radiation technology, research into the use of intensitymodulated radiation therapy (IMRT) for esophageal cancer treatment has shown improved outcomes. ${ }^{11,12}$ On the other hand, the decision to undertake surgery requires careful consideration for fear of high morbidity and mortality rates following thoracotomy and laparotomy in these patients. ${ }^{13,14}$ For the moment, the optimal treatment for patients with locally advanced ESCC located in the middle or upper esophagus is still inconclusive. It would be valuable to identify useful biomarkers to select the patients who are most likely to benefit from surgery or dCRT.

A mounting body of evidence has revealed that a systemic inflammatory response has a vital role in cell proliferation, invasion and migration as well as the response to treatment. ${ }^{15,16}$ Various clinical inflammatory biomarkers, such as the neutrophil-to-lymphocyte ratio (NLR) and platelet-to-lymphocyte ratio (PLR), have been well authenticated to predict clinical outcomes in numerous types of cancer. ${ }^{17-22}$ Among these biomarkers, pretreatment NLR and pretreatment PLR can be easily measured and are inexpensive tests. Both of them have been verified to be linked with tumor prognosis in ESCC patients who receive esophagectomy or dCRT. ${ }^{22,23}$ However, there has no study reported the pretreatment NLR and pretreatment PLR as reference markers of treatment decision between esophagectomy and dCRT for locally advanced ESCC in middle or upper esophagus patients.
In the present study, the locally advanced ESCC located in the middle or upper esophagus of patients who received esophagectomy and dCRT in our hospital were retrospectively reviewed. The objective was to evaluate the application of pretreatment NLR and pretreatment PLR in selected patients for esophagectomy or dCRT. We also analyzed the linkage between pretreatment NLR/ PLR and progression-free survival (PFS)/overall survival (OS) in this subset of patients.

\section{Methods}

\section{Patients Selection}

We retrospectively reviewed patients with locally advanced ESCC in the middle or upper esophagus who were seeking a radical cure at Ningbo Medical Center Lihuili Hospital between January 2014 and December 2019. The inclusion criteria were as follows: 1) a pathology diagnosis of ESCC; 2) tumors located in the middle or upper part of the esophagus (classified by the staging system of the seventh American Joint Committee on Cancer); 3) received curative esophagectomy or dCRT; 4) surgery without preoperative adjuvant chemotherapy and/or radiotherapy; 5) previously untreated; 6) locally advanced status, stage $\mathrm{T} 3 / 4 \mathrm{~N}_{\text {any }}$ or $\mathrm{T}_{\text {any }} \mathrm{N}+$, without distant metastasis or abdominal lymph node metastasis; 7) no chronic or acute inflammatory condition (according to a normal $\mathrm{C}$-reaction protein status at baseline examination). A total of 113 patients were enrolled. The pretreatment stage was made on the basis of the results of esophagogastroscopy/endoscopic ultrasonography, computed tomography (CT) examination, barium swallow, and bone and positron emission tomography (PET) scans. The stage of patients with curative esophagectomy was replaced by the postoperative staged. The patients were classified based on the TNM staging system of the seventh American Joint Committee on Cancer.

\section{Data Collection and Definitions}

Clinical characteristics and pathological findings, including age, drinking history, smoking history and tumor length were carefully recorded. The following hematology indexes were evaluated up to 1 week before treatment: neutrophil count $\left(\times 10^{9} / \mathrm{L}\right)$, platelet count $\left(\times 10^{9} / \mathrm{L}\right)$ and lymphocyte count $\left(\times 10^{9} / \mathrm{L}\right)$. We defined the NLR as the neutrophil count divided by the lymphocyte count. Similarly, PLR was calculated as the ratio of the platelet count to the lymphocyte count. 


\section{Treatment Protocol \\ Surgery Group}

The operative procedure was a traditional right anterolateral thoracotomy with laparotomy or thoracoscopic esophagectomy in the prone position. The safety of the resected proximal boundary of the esophagus was guaranteed by intraoperative histological analysis of a frozen section of the proximal margin. Four cycles of adjuvant chemotherapy were given after surgery. The chemotherapy regimen was platinum combined with paclitaxel once every 3 weeks per cycle.

\section{Chemoradiotherapy Group}

These patients were treated with IMRT to guarantee tumor coverage and safeguard adjacent normal organs. Delineation of target tumor volume depended on the examination, such as barium swallow, esophagogastroscopy, CT and PET scans. The gross target volume (GTV) was designated as the primary tumor and metastatic lymph nodes, while the clinical target volume (CTV) was defined as the primary tumor plus a $3-4 \mathrm{~cm}$ expansion superiorly and inferiorly along the length of the esophagus. A $1 \mathrm{~cm}$ radial expansion, which should also include supraclavicular regions. The planning target volume (PTV) was defined as the CTV expanded by $0.5-0.8 \mathrm{~cm}$ margins in all directions. A dose of $50 \mathrm{~Gy}$ (2 Gy/fraction, 5 days per week) was given to PTV, following a boost dose to GTV for an extra 10 Gy in 5 daily fractions. The concurrent chemotherapy regimen was platinum combined with paclitaxel or fluorouracil once every 4 weeks per cycle. One or two courses of chemotherapy were performed during radiotherapy. Two or three cycles of adjuvant chemotherapy were followed by radiotherapy.

\section{Follow-Up Assessments}

Follow-up evaluations, including a thorough clinical examination and CT scan, were performed every 3 months for the first year, every 6 months for 2 years, and annually thereafter. Diagnostic examinations were performed when recurrence was suspected. OS was calculated from the date of initiation of therapy to the time of death from any reason or terminal time of follow-up, which was the primary end point of assessment. Secondary assessment endpoints were PFS, which was defined as the time between the onset of therapy and the progression or last time of follow-up.

\section{Statistical Analysis}

The statistical analyses were performed using a social science statistical software package, version 26.0 (SPSS Inc., Chicago, IL, US), and the best cut-off value of the NLR and PLR were determined using the receiver operating characteristic (ROC) curve. The categorical variables were analyzed with Fisher's exact or chi-square tests. The survival curves were plotted by the KaplanMeier method and any differences were determined using a Log rank test. Predictors for survival were assessed by univariate and multivariate Cox regression analyses. Statistical significance was deemed to be a $P$-value $<0.05$.

\section{Results}

\section{Patient and Treatment Characteristics}

A total of 113 patients who met the inclusion criteria were chosen for our research study. The median age was 62 years (range from 47 to 80 years) and the majority of patients were male $(n=99,87.6 \%)$. Primary tumors were located in the upper esophagus in 25 patients (22.1\%), in the middle esophagus in 61 patients $(54.0 \%)$, and in both regions in 27 patients $(23.9 \%)$. A more detailed information of patient characteristics and baseline are shown in Table 1.

Radical surgery was carried out on 60 patients (53.1\%) and dCRT was administered to 53 patients (46.9\%), 42 (79.2\%) of whom received concurrent dCRT with 2 cycles of chemotherapy. With a median follow-up time of 19 months (range from 5 to 75.2 months), 83 patients $(73.5 \%)$ were dead and 93 patients $(82.3 \%)$ were recrudescent at the end of the follow-up time. The median OS and PFS for the whole cohort of patients were 20 months and 15.2 months, respectively. For the surgery group, the median OS and PFS were 21.2 months and 16.5 months, and respectively 20 months and 15 months for the dCRT group. No survival difference between the surgery group and dCRT group was revealed by Kaplan-Meier analysis (Figure 1A and $\mathrm{B}, P>0.05)$.

\section{Optimal Cut-Off Values for NLR and PLR}

We used the ROC curve to determine the optimal cut-off values for NLR and PLR for all patients in the study. For NLR, the optimal cut-off value was 2.07 with 0.737 (95\% CI: $0.635-0.840)$ of the area under the curve (AUC). The sensitivity and specificity were 0.735 and 
Table I Basic Clinicopathological Characteristics of II3 ESCC Patients

\begin{tabular}{|c|c|}
\hline Characteristics & Patients (\%) \\
\hline \multicolumn{2}{|l|}{ Age (years) } \\
\hline Median & 62 years \\
\hline Range & $47-80$ \\
\hline$<65$ & $70(61.1 \%)$ \\
\hline$\geq 65$ & 43 (38.9\%) \\
\hline \multicolumn{2}{|l|}{ Gender } \\
\hline Male & 99 (87.6\%) \\
\hline Female & 14 (I2.4\%) \\
\hline \multicolumn{2}{|l|}{ Drinking history } \\
\hline Yes & 81 (7I.7\%) \\
\hline No & $32(28.3 \%)$ \\
\hline \multicolumn{2}{|l|}{ Smoking history } \\
\hline Yes & $83(73.5 \%)$ \\
\hline No & $30(26.5 \%)$ \\
\hline \multicolumn{2}{|l|}{ Tumor location } \\
\hline Upper & $25(22.1 \%)$ \\
\hline Middle & $6 \mathrm{I}(54.0 \%)$ \\
\hline Both areas & $27(23.9 \%)$ \\
\hline \multicolumn{2}{|l|}{ Tumor length $(\mathrm{cm})$} \\
\hline Median & 4.8 \\
\hline Range & $2-8.2$ \\
\hline$<5$ & 59 (52.2\%) \\
\hline$\geq 5$ & 54 (47.8\%) \\
\hline \multicolumn{2}{|l|}{ T-staging } \\
\hline $\mathrm{T} 2$ & $4(3.5 \%)$ \\
\hline $\mathrm{T} 3$ & $86(76.1 \%)$ \\
\hline $\mathrm{T} 4$ & $16(14.2 \%)$ \\
\hline$x$ & $7(6.2 \%)$ \\
\hline \multicolumn{2}{|l|}{$\mathrm{N}$-staging } \\
\hline No & $20(17.7 \%)$ \\
\hline $\mathrm{NI}$ & 57 (50.4\%) \\
\hline N2 & 27 (23.9\%) \\
\hline N3 & $9(8.0 \%)$ \\
\hline \multicolumn{2}{|l|}{ Tumor stage } \\
\hline II & $20(17.7 \%)$ \\
\hline III & $93(82.3 \%)$ \\
\hline \multicolumn{2}{|l|}{ Therapeutic modalities } \\
\hline Radical surgery & $60(53.1 \%)$ \\
\hline dCRT & $53(46.9 \%)$ \\
\hline
\end{tabular}

0.667, respectively. For PLR, the optimal cut-off value was 183.06 with 0.660 (95\% CI: $0.552-0.767)$ of the AUC. The sensitivity and specificity were 0.566 and 0.733. The ROC curves are presented in Figure $2 \mathrm{~A}$ and $\mathrm{B}$.

\section{Correlation Between NLR and PLR and} Clinicopathological Parameters in the Overall Population

Before treatment, 73 (64.6\%) patients had a high NLR > 2.07 and $40(35.4 \%)$ patients had a low NLR $\leq 2.07$. In addition, $54(47.8 \%)$ patients had a high PLR $>183.06$ and $59(52.5 \%)$ patients had a low PLR $\leq 183.06$. The NLR was closely associated with the extent of lymph node metastasis $(P=0.045)$ and the tumor stage $(P=$ 0.043). A significant correlation was observed between PLR and the extent of lymph node metastasis $(P=$ 0.002). Additionally, a high PLR and recurrence with distant organ metastasis were closely related $(P=$ 0.014). The associations of NLR and PLR with the clinical and pathologic characteristics are presented in Table 2 .

\section{Prognostic Factors for Prognosis in the Overall Population}

Univariate analyses revealed that NLR (>2.07), PLR $(>183.06)$, depth of tumor (T3/T4), lymph node metastasis (N2/N3) and advanced stage (III) were all noteworthy risk factors for poor OS or PFS (Table 3). The results of multivariate analysis demonstrated that NLR $(>2.07)$ and PLR (>183.06) were independently associated with poor OS or PFS, and advanced stage (III) were significantly correlated with decreased OS (Table 4).

\section{Prognostic Effect of NLR and PLR in the Overall Population}

For high NLR, the 1-year, 3-year, and 4-year OS were respectively $88.9 \%, 16.8 \%$, and $0 \%$, with $62.7 \%, 3.3 \%$, and $0 \%$ of the 1-year, 3-year, and 4-year PFS. For low NLR, the 1, 3, and 4-year OS were respectively $97.4 \%$, $46.2 \%$, and $24.7 \%$, with $89.7 \%, 15.7 \%$, and $5.2 \%$ of the 1 , 3, and 4-year PFS. Kaplan-Meier analysis revealed that a low NLR was associated with superior survival benefits $(P=0.000$, Figure 3A). Similarly, for high PLR, the 1, 3, and 4-year OS were respectively $81.1 \%, 15.9 \%$, and $4 \%$, with $60.6 \%, 0 \%$, and $0 \%$ of the 1,3 , and 4 -year PFS. For low PLR, the 1, 3, and 4-year OS were respectively $93.1 \%, 37.4 \%$, and $13.5 \%$, with $82.8 \%, 15.3 \%$, and $3.8 \%$ of the 1, 3, and 4-year PFS. Kaplan-Meier analysis confirmed that low PLR was associated with the added advantage of survival $(P=0.000$, Figure 3B). 

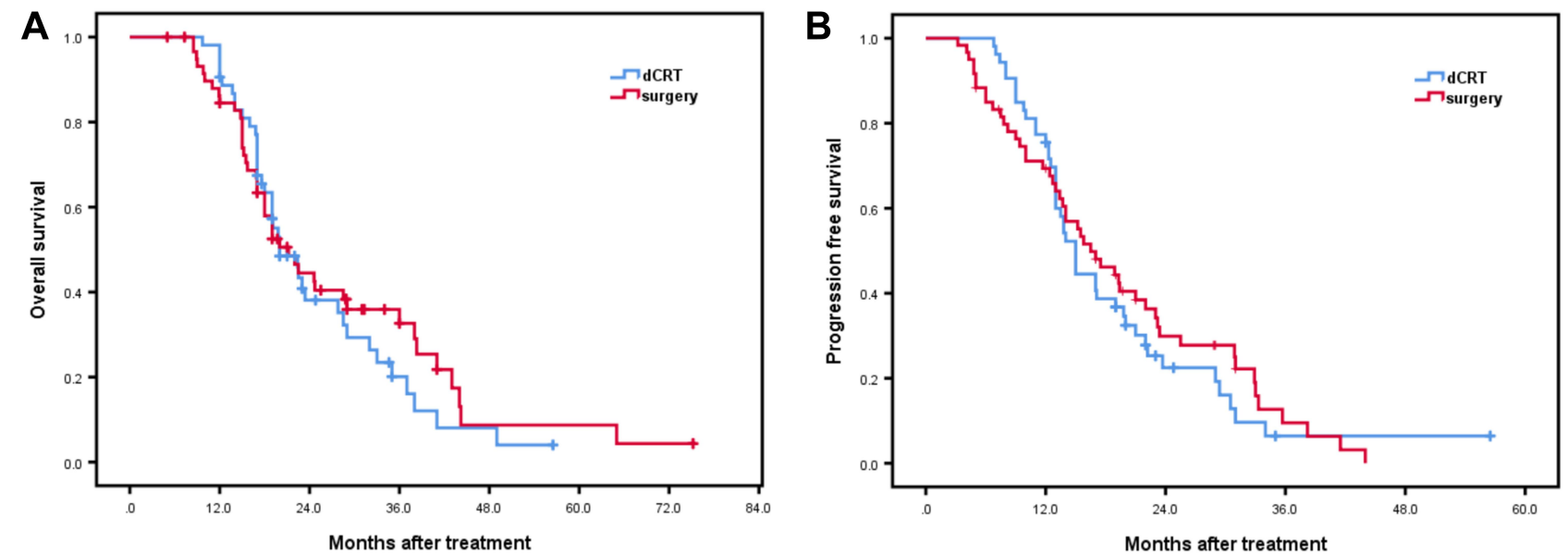

Figure I Association of therapeutic modalities of surgery versus definitive chemoradiotherapy (dCRT) with overall survival $(\mathbf{A}, P=0.567)$ and progression-free survival $(\mathbf{B}$, $P=0.642)$ in the overall population.
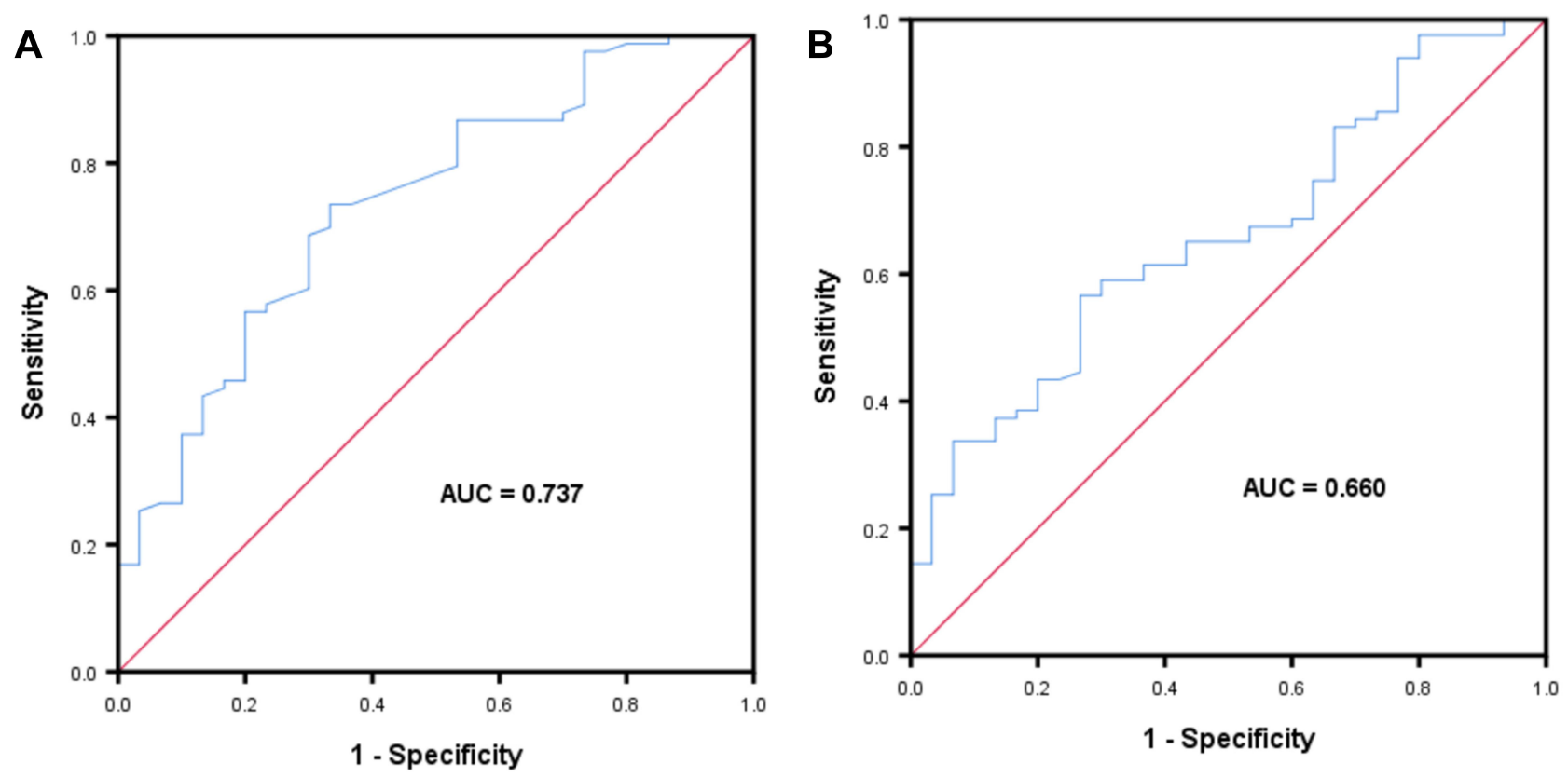

Figure 2 Receiver operating curves for overall survival were plotted to determine the optimum cut-off for NLR (A), PLR (B).

\section{Prognostic Effect of Therapeutic Modalities by NLR and PLR}

In the high NLR and PLR populations or the low PLR population, survival benefit was not different between surgery and dCRT (Figure 4A-C). It is noteworthy that surgery was associated with a superior OS compared with dCRT in the low NLR population $(P=0.045)$. Figure 4D), whose clinicopathological parameters were no difference between surgery and dCRT (Table 5). However, there was no significant relationship between therapeutic modalities and PFS in the low NLR cohort of patients $(P=0.099)$.

\section{Discussion}

A systemic inflammatory response, that triggers the proliferation and metastasis of tumor cells through DNA damage and the facilitation of angiogenesis, substantially promotes the development of malignancies and affects survival of patients with cancer. ${ }^{16,24}$ Neutrophils are able to secrete cytokines and chemokines including interleukin1 , interleukin-6, tumor necrosis factor and myeloid growth factors, which promote tumor progression, inhibit the ability of immune cells to suppress immune functions and induce resistance to cytotoxic drugs. ${ }^{16,25,26}$ Additionally, 
Table 2 Associations of NLR and PLR with Clinicopathological Characteristics

\begin{tabular}{|c|c|c|c|c|c|c|}
\hline \multirow[t]{2}{*}{ Characteristics } & \multicolumn{3}{|l|}{ NLR } & \multicolumn{3}{|l|}{ PLR } \\
\hline & $\leq 2.07$ & $>2.07$ & $P$-value & $\leq 183.06$ & $>183.06$ & $P$-value \\
\hline Age (years) & & & 0.621 & & & $0.86 I$ \\
\hline$<65$ & $26(23.0 \%)$ & 44 (38.9\%) & & 37 (32.7\%) & 33 (29.2\%) & \\
\hline$\geq 65$ & $14(12.4 \%)$ & 29 (25.7\%) & & $22(19.5 \%)$ & $21(18.6 \%)$ & \\
\hline Gender & & & 0.533 & & & 0.454 \\
\hline Male & $34(30.1 \%)$ & 65 (57.5\%) & & 53 (46.9\%) & $46(40.7 \%)$ & \\
\hline Female & $6(5.3 \%)$ & 8 (7.1\%) & & $6(5.3 \%)$ & $8(7.1 \%)$ & \\
\hline Drinking history & & & 0.109 & & & 0.338 \\
\hline Yes & 25 (22.1\%) & 56 (49.6\%) & & 40 (35.4\%) & $4 \mid$ (36.3\%) & \\
\hline No & $15(13.3 \%)$ & 17 (I4.1\%) & & $19(16.8 \%)$ & $13(11.5 \%)$ & \\
\hline Smoking history & & & 0.289 & & & 0.319 \\
\hline Yes & 27 (23.9\%) & 56 (49.6\%) & & $4 \mathrm{I}(36.3 \%)$ & 42 (37.2\%) & \\
\hline No & $13(11.5 \%)$ & 17 (I5.0\%) & & 18 (I5.9\%) & $12(10.6 \%)$ & \\
\hline Tumor location & & & 0.365 & & & 0.137 \\
\hline Upper & $8(7.1 \%)$ & 17 (I5.0\%) & & $9(8 \%)$ & $16(14.2 \%)$ & \\
\hline Middle & $25(22.1 \%)$ & 36 (31.9\%) & & $33(29.2 \%)$ & $28(24.8 \%)$ & \\
\hline Both areas & 7 (6.2\%) & $20(\mid 7.7 \%)$ & & 17 (I5.0\%) & $10(8.8 \%)$ & \\
\hline Tumor length $(\mathrm{cm})$ & & & 0.661 & & & 0.616 \\
\hline$<5$ & $22(19.5 \%)$ & 37 (32.7\%) & & $29(25.7 \%)$ & $30(26.5 \%)$ & \\
\hline$\geq 5$ & $18(15.9 \%)$ & 36 (31.9\%) & & $30(26.5 \%)$ & $24(21.3 \%)$ & \\
\hline T-staging & & & 0.539 & & & 0.264 \\
\hline T2 & $2(1.9 \%)$ & $2(1.9 \%)$ & & $3(2.8 \%)$ & I (0.9\%) & \\
\hline T3 & $32(30.2 \%)$ & $54(50.9 \%)$ & & $43(40.6 \%)$ & $43(40.6 \%)$ & \\
\hline T4 & $4(3.8 \%)$ & $12(11.3 \%)$ & & II (I0.4\%) & $5(4.7 \%)$ & \\
\hline$N$-staging & & & 0.045 & & & 0.002 \\
\hline $\mathrm{N} 0+\mathrm{NI}$ & $32(28.3 \%)$ & $45(39.8 \%)$ & & $48(42.5 \%)$ & $29(25.7 \%)$ & \\
\hline $\mathrm{N} 2+\mathrm{N} 3$ & $8(7.1 \%)$ & $28(24.8 \%)$ & & II (9.7\%) & $25(22.1 \%)$ & \\
\hline Tumor stage & & & 0.043 & & & 0.442 \\
\hline II & II (9.7\%) & $9(8.0 \%)$ & & $12(10.6 \%)$ & $8(7.1 \%)$ & \\
\hline III & $29(25.7 \%)$ & $64(56.6 \%)$ & & $47(4 I .6 \%)$ & $46(40.7 \%)$ & \\
\hline Therapeutic modalities & & & 0.095 & & & 0.616 \\
\hline Surgery & $17(15.0 \%)$ & $43(38.1 \%)$ & & $30(26.5 \%)$ & $30(26.5 \%)$ & \\
\hline dCRT & $23(20.4 \%)$ & $30(26.5 \%)$ & & $29(25.7 \%)$ & $24(21.3 \%)$ & \\
\hline Recurrence with distant organs metastasis & & & 0.284 & & & 0.014 \\
\hline Yes & $8(8.7 \%)$ & $27(29.3 \%)$ & & II (II.9\%) & $24(26.1 \%)$ & \\
\hline No & 19 (20.7\%) & 38 (4I.3\%) & & 33 (35.9\%) & $24(26.1 \%)$ & \\
\hline
\end{tabular}

platelets are a critical source of cytokines, such as transforming growth factor- $\beta$ and vascular endothelial growth factor (VEGF), which assist angiogenesis and cell invasion. Moreover, lymphocytes can secrete several cytokines, including IFN- $\gamma$ and $\mathrm{TNF}-\alpha$, to prevent tumor development from immune compartments and regulate the immunosurveillance process. The decreased lymphocyte count suggests inadequate host-to-tumor immunological reactions, with reduced responses against tumor. $^{26-28}$ Taken together, these cells interact to form an inflammatory immune system, which have two main functions (anti-tumor and tumor promoting) under different conditions. Several previous studies have shown that systemic inflammation parameters, such as NLR, PLR and 
Table 3 Univariate Analysis of Factors Associated with Overall Survival and Progression-Free Survival

\begin{tabular}{|c|c|c|c|c|c|c|c|}
\hline \multirow[t]{2}{*}{ Prognostic Factors } & \multirow[t]{2}{*}{ Patients } & \multicolumn{3}{|c|}{ Overall Survival } & \multicolumn{3}{|c|}{ Progression-Free Survival } \\
\hline & & HR & $95 \% \mathrm{Cl}$ & $P$-value & HR & $95 \% \mathrm{Cl}$ & $P$-value \\
\hline \multicolumn{8}{|l|}{ Age (years) } \\
\hline$<65$ & 70 & 1 & & & I & & \\
\hline$\geq 65$ & 43 & 1.005 & $0.642-1.573$ & $0.98 \mathrm{I}$ & $0.88 I$ & $0.575-1.350$ & $0.56 \mathrm{I}$ \\
\hline \multicolumn{8}{|l|}{ Gender } \\
\hline Female & 14 & 1 & & & I & & \\
\hline Male & 99 & 1.106 & $0.569-2.151$ & 0.766 & $1.34 \mid$ & $0.693-2.595$ & 0.384 \\
\hline \multicolumn{8}{|l|}{ Drinking history } \\
\hline No & 32 & 1 & & & 1 & & \\
\hline Yes & 81 & 1.348 & $0.820-2.217$ & 0.239 & 1.326 & $0.826-2.129$ & 0.242 \\
\hline \multicolumn{8}{|l|}{ Smoking history } \\
\hline No & 30 & 1 & & & I & & \\
\hline Yes & 83 & 1.225 & $0.738-2.033$ & 0.432 & 1.391 & $0.852-2.272$ & 0.187 \\
\hline \multicolumn{8}{|l|}{ Tumor location } \\
\hline Upper & 25 & 1 & & & I & & \\
\hline Middle & 61 & 0.951 & $0.502-1.804$ & 0.878 & 0.895 & $0.491-1.634$ & 0.719 \\
\hline Both areas & 27 & 1.183 & $0.690-2.028$ & 0.542 & 1.073 & $0.649-1.775$ & 0.783 \\
\hline \multicolumn{8}{|l|}{ Tumor length $(\mathrm{cm})$} \\
\hline$<5$ & 60 & 1 & & & I & & \\
\hline$\geq 5$ & 53 & 1.074 & $0.693-1.665$ & 0.749 & 1.119 & $0.739-1.695$ & 0.594 \\
\hline \multicolumn{8}{|l|}{ T-staging } \\
\hline $\mathrm{T} 2$ & 4 & 1 & & & $\mathrm{I}$ & & \\
\hline $\mathrm{T} 3+\mathrm{T} 4$ & 102 & 4.309 & $1.032-17.988$ & 0.045 & 3.009 & $1.043-8.682$ & 0.042 \\
\hline \multicolumn{8}{|l|}{$\mathrm{N}$-staging } \\
\hline $\mathrm{N} 0+\mathrm{NI}$ & 77 & I & & & I & & \\
\hline $\mathrm{N} 2+\mathrm{N} 3$ & 36 & 2.218 & $1.394-3.528$ & 0.001 & 1.750 & $1.120-2.736$ & 0.014 \\
\hline \multicolumn{8}{|l|}{ Tumor stage } \\
\hline II & 20 & I & & & I & & \\
\hline III & 93 & 3.336 & $1.680-6.623$ & 0.001 & 2.208 & $1.238-3.937$ & 0.007 \\
\hline \multicolumn{8}{|l|}{ Therapeutic modalities } \\
\hline dCRT & 53 & 1 & & & I & & \\
\hline Surgery & 60 & 0.882 & $0.570-1.365$ & 0.573 & 0.908 & $0.602-1.369$ & 0.645 \\
\hline \multicolumn{8}{|l|}{ NLR } \\
\hline$\leq 2.07$ & 40 & 1 & & & I & & \\
\hline$>2.07$ & 73 & 3.007 & $1.788-5.059$ & 0.000 & 2.470 & $1.550-3.936$ & 0.000 \\
\hline \multicolumn{8}{|l|}{ PLR } \\
\hline$\leq 183.06$ & 59 & 1 & & & I & & \\
\hline$>183.06$ & 54 & 2.431 & $1.560-3.789$ & 0.000 & 2.087 & $1.373-3.174$ & 0.001 \\
\hline
\end{tabular}

lymphocyte-to-monocyte ratio, are commonly supposed to identify the prognosis of various solid tumors. ${ }^{23,29-32}$ Therefore, NLR and PLR are proposed as easily determinable and cost-effective inflammatory biomarkers that reflect the anti-tumor or tumor-promoting function of the inflammatory immune system. In our retrospective study, we selected NLR and PLR to evaluate the prognosis in patients with ESCC in the middle and upper esophagus. In agreement with most previously published reports, ${ }^{23,33}$ both pretreatment high NLR $(>2.07)$ and pretreatment 
Table 4 Multivariate Analysis of Factors Associated with Overall Survival and Progression-Free Survival

\begin{tabular}{|c|c|c|c|c|c|c|}
\hline \multirow[t]{2}{*}{ Prognostic Factors } & \multicolumn{3}{|c|}{ Overall Survival } & \multicolumn{3}{|c|}{ Progression-Free Survival } \\
\hline & HR & $95 \% \mathrm{Cl}$ & p value & HR & $95 \% \mathrm{Cl}$ & $P$-value \\
\hline T-staging (T2 vs T3+T4) & 2.397 & $0.538-10.673$ & 0.251 & 2.283 & $0.735-7.088$ & 0.153 \\
\hline $\mathrm{N}$-staging $(\mathrm{N} 0+\mathrm{NI}$ vs $\mathrm{N} 2+\mathrm{N} 3)$ & 1.191 & $0.703-2.021$ & 0.516 & 1.023 & $0.603-1.734$ & 0.933 \\
\hline Tumor stage (II vs III) & 2.210 & $1.003-4.725$ & 0.041 & 1.573 & $0.818-3.027$ & 0.175 \\
\hline NLR ( $\leq 2.07$ vs $>2.07)$ & 1.982 & $1.13 \mid-3.474$ & 0.017 & 1.764 & $1.060-2.936$ & 0.029 \\
\hline PLR $(\leq 183.06$ vs $>183.06)$ & 2.033 & I.240-3.334 & 0.005 & 1.857 & $1.149-3.001$ & 0.011 \\
\hline
\end{tabular}

high PLR (>183.06) are strongly related to a worse PFS and OS compared with low indexes in these patients treated with surgery or dCRT.

Multivariate logistic regression analysis revealed that pretreatment NLR and PLR values were closely associated with survival. But equally, T-staging and $\mathrm{N}$-staging were calculated as an uncorrelated result with survival, besides, tumor stage had been turned out to be not statistically significant with PFS. The above negative results were considered to be due to a lower population among the T2, N3 and stage II. Moreover, both pretreatment high NLR and PLR were correlated with lymph node metastasis (N2/N3) of ESCC patients with tumors located in the middle or upper esophagus. However, stage III was only significantly associated with pretreatment high NLR but not pretreatment high PLR. This negative result may be attributed to the small number of stage II cases examined. Additionally, we found the relationship that pretreatment high PLR patients had a high rate of recurrence with distant organ metastasis. This finding may be explained by the physiological mechanism of platelets. Platelets can protect circulating tumor cells from shear stresses as they circulate in the bloodstream, induce VEGF and epithelialmesenchymal transition, and promote tumor cell extravasation, adhesion and seeding of distant organ sites. ${ }^{34-36}$

During clinical practice, different specialists have expressed different opinions on whether to choose surgery or dCRT for locally advanced ESCC, but there is no unified standard at present. In China, the great majority of patients are recommended to have surgical treatment, unless they are inoperable, of venerable age, suffering from underlying diseases or for various other reasons. However, poor prognosis of these patients and postoperative complications including esophageal fistula, infection and insufficient surgical margin should be considered prior to opting for surgical treatment. This is especially important for patients with locally advanced ESCC in the middle or upper esophagus, who are more likely to be recommended dCRT. It is difficult to make a distinction between populations that benefited from surgery and dCRT by all kinds of tests. To the best of our knowledge, there are few hematological biomarkers to guide the treatment decision between surgery and dCRT. As our study has confirmed, NLR and PLR, easily available inflammatory biomarkers,
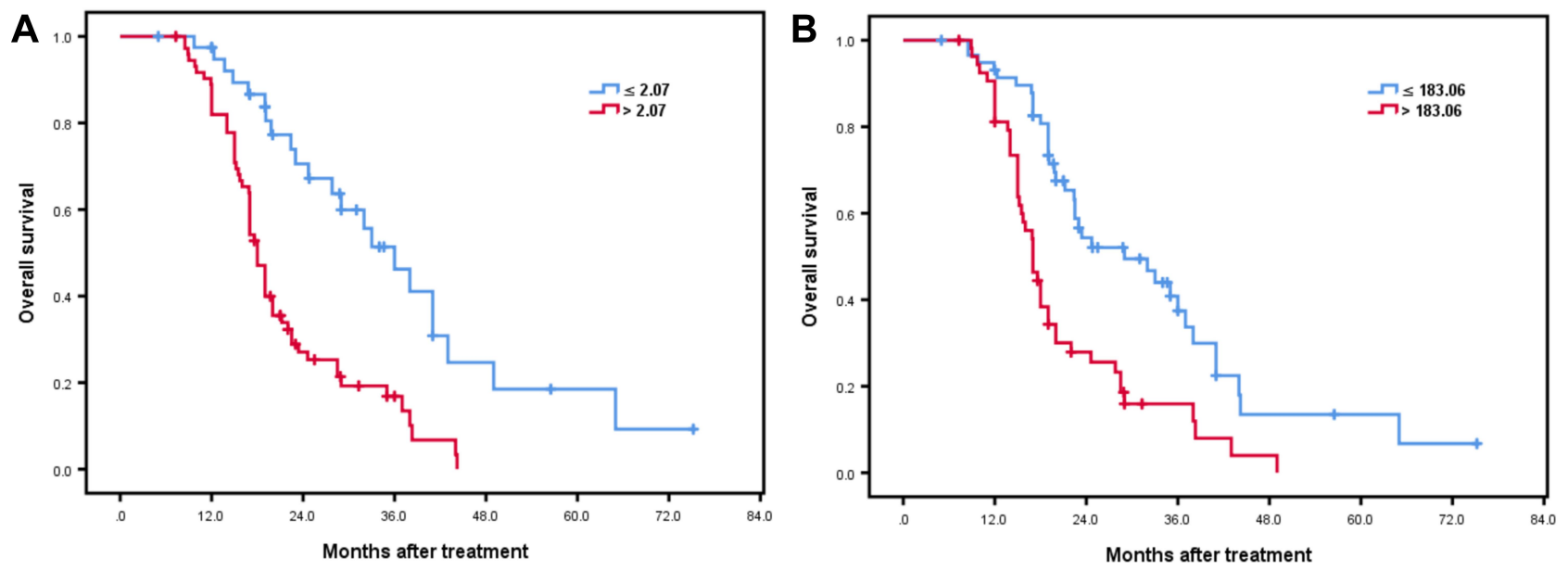

Figure 3 Association of NLR $(>2.07$ versus $\leq 2.07)$ or PLR $(>183.06$ versus $\leq 183.06)$ with overall survival $(\mathbf{A}, P=0.000$ and $\mathbf{B}, P=0.000)$. 

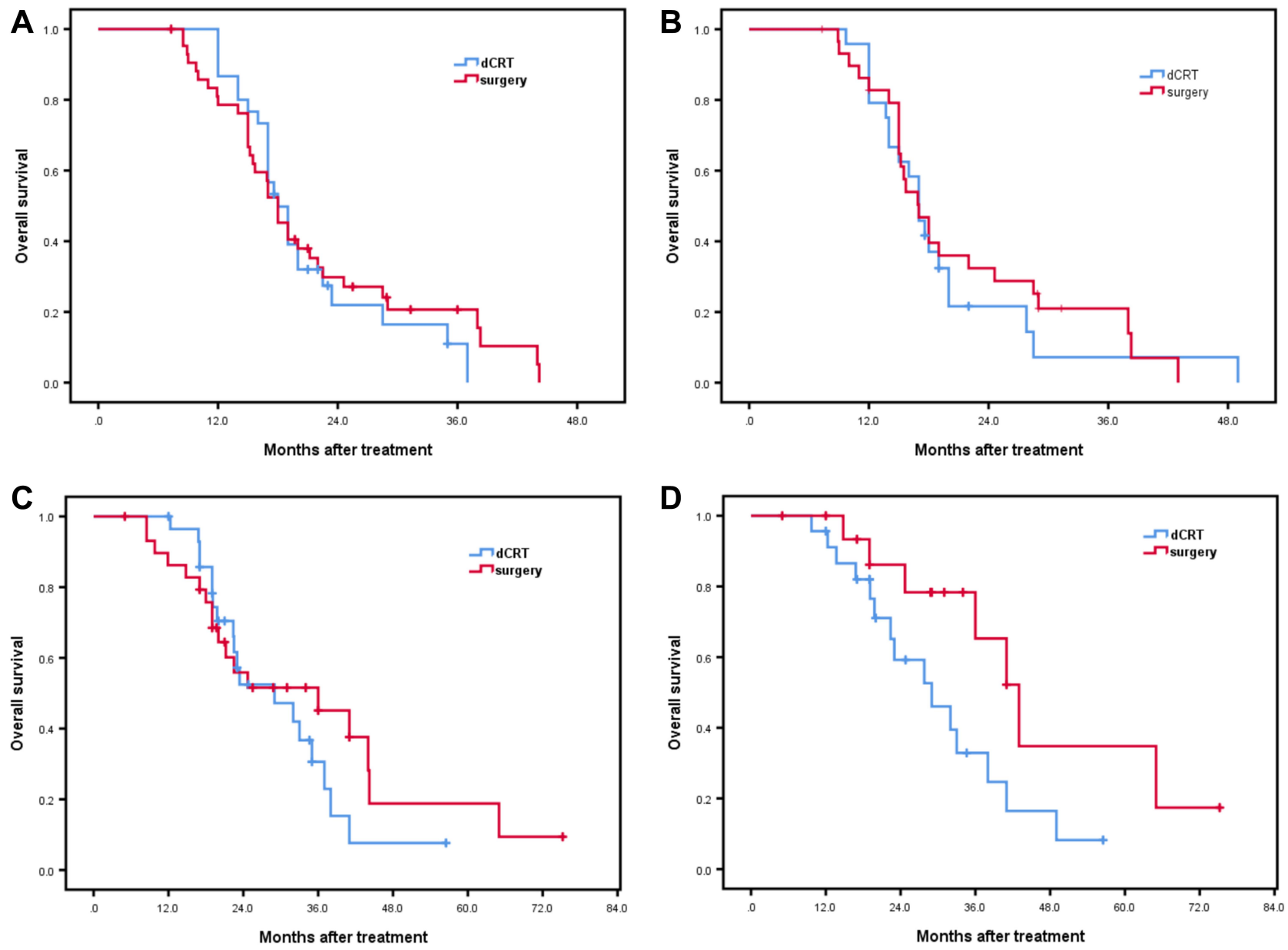

Figure 4 Association of therapeutic modalities of surgery versus definitive chemoradiotherapy (dCRT) with overall survival in high NLR population $(A, P=0.768)$, high PLR population (B, $P=0.678)$, low PLR population $(C, P=0.45 I)$ and low NLR population $(D, P=0.045)$.

can predict the prognosis of ESCC patients undergoing surgery or dCRT. In addition, the present study has also further clarified that surgery is superior to dCRT for the treatment of patients with locally advanced ESCC in the middle and upper esophagus and with a pretreatment low NLR $(\leq 2.07)$. The median OS of the surgery group of 17 patients (43 months) showed a definite improvement compared with the dCRT group of 23 patients ( 29 months) in a population with a pretreatment low NLR. Although the sample size was small, there was no significant difference in case characteristics between the two groups. The median PFS of the surgery group (31 months) was apparently longer than for the dCRT group (21 months), although the apparent difference was not statistically significant. This negative result may be due to the small sample size. In conclusion, we have reason to believe that surgery is better than dCRT for the treatment of patients with locally advanced ESCC in the middle and upper esophagus with a pretreatment low NLR. Compared to surgery, we must consider the following two effects of radiotherapy. First, radiotherapy can trigger a strong tumor-associated inflammatory response by causing massive necrotic death of cancer cells and surrounding tissues. ${ }^{27,37}$ Second, lymphocytopenia can be induced by conventional radiotherapy. ${ }^{38}$

The present research provides the first clinical evidence that the pretreatment NLR value as a reference biomarker can guide the treatment selections (surgery or dCRT). However, there are several limitations to this research. Our cohort involved a single center and was retrospective in nature, which may lead to bias. In addition, the sample size was relatively small. Finally, unknown other factors, including subsequent therapy, may potentially have affected the patient outcomes.

\section{Conclusions}

The pretreatment NLR and PLR, easy-to-use hematological markers, were independent prognostic indicators for patients with locally advanced ESCC located in the middle 
Table 5 Clinicopathological Characteristics Between Surgery and dCRT in Low NLR Population

\begin{tabular}{|c|c|c|c|}
\hline \multirow[t]{2}{*}{ Characteristics } & \multicolumn{3}{|c|}{ Therapeutic Modality } \\
\hline & Surgery & dCRT & $P$-value \\
\hline $\begin{array}{l}\text { Age (years) } \\
\quad<65 \\
\quad \geq 65\end{array}$ & $\begin{array}{l}10(25.0 \%) \\
7(17.5 \%)\end{array}$ & $\begin{array}{l}16 \text { (40.0\%) } \\
7(17.5 \%)\end{array}$ & $0.48 \mathrm{I}$ \\
\hline $\begin{array}{l}\text { Gender } \\
\text { Male } \\
\text { Female }\end{array}$ & $\begin{array}{l}15(37.5 \%) \\
2(5.0 \%)\end{array}$ & $\begin{array}{l}19(47.5 \%) \\
4(1.0 \%)\end{array}$ & 0.622 \\
\hline $\begin{array}{l}\text { Drinking history } \\
\text { Yes } \\
\text { No }\end{array}$ & $\begin{array}{l}12(30.0 \%) \\
5(12.5 \%)\end{array}$ & $\begin{array}{l}13(32.5 \%) \\
10(25.0 \%)\end{array}$ & 0.364 \\
\hline $\begin{array}{l}\text { Smoking history } \\
\text { Yes } \\
\text { No }\end{array}$ & $\begin{array}{l}12(30.0 \%) \\
5(12.5 \%)\end{array}$ & $\begin{array}{l}15(37.5 \%) \\
8(20.0 \%)\end{array}$ & 0.720 \\
\hline $\begin{array}{l}\text { Tumor location } \\
\text { Upper } \\
\text { Middle } \\
\text { Both areas }\end{array}$ & $\begin{array}{l}3(7.5 \%) \\
12(30.0 \%) \\
2(5.0 \%)\end{array}$ & $\begin{array}{l}5(12.5 \%) \\
13(32.5 \%) \\
5(12.5 \%)\end{array}$ & 0.623 \\
\hline $\begin{array}{l}\text { Tumor length }(\mathrm{cm}) \\
\quad<5 \\
\geq 5\end{array}$ & $\begin{array}{l}12(30.0 \%) \\
5(12.5 \%)\end{array}$ & $\begin{array}{l}10(25.0 \%) \\
13(32.5 \%)\end{array}$ & 0.088 \\
\hline $\begin{array}{l}\text { T-staging } \\
\text { T2 } \\
\text { T3+T4 }\end{array}$ & $\begin{array}{l}2(5.3 \%) \\
15(39.5 \%)\end{array}$ & $\begin{array}{l}0(0 \%) \\
21(55.2 \%)\end{array}$ & 0.106 \\
\hline $\begin{array}{r}\mathrm{N} \text {-staging } \\
\mathrm{N} 0+\mathrm{NI} \\
\mathrm{N} 2+\mathrm{N} 3\end{array}$ & $\begin{array}{l}15(37.5 \%) \\
2(5.0 \%)\end{array}$ & $\begin{array}{l}17(42.5 \%) \\
6(15.0 \%)\end{array}$ & 0.263 \\
\hline $\begin{array}{l}\text { Tumor stage } \\
\text { II } \\
\text { III }\end{array}$ & $\begin{array}{l}6(15.0 \%) \\
\text { II (27.5\%) }\end{array}$ & $\begin{array}{l}5(12.5 \%) \\
18(45.0 \%)\end{array}$ & 0.343 \\
\hline
\end{tabular}

or upper esophagus that underwent radical surgery or dCRT. A low pretreatment NLR value was regarded as a reference marker to use radical surgery more certain as it produced a considerable therapeutic benefit.

\section{Ethics Statement}

The article and data were approved by the Ningbo Medical Center Lihuili Hospital ethics committee. The patients' medical records and other involved information were used in our research according to patients' permission. Besides, the authors would obey the declaration of Helsinki to use the information for the purposes of the research. As a retrospective review, patients' requirement of looking back their medical records were allowed by our committee. The patients' names or other privacy were anonymized with confidentiality while patient informed consent was obtained.

\section{Acknowledgment}

We thank Qinhong Lu and her colleague (Department of Clinical Laboratory, Ningbo Medical Center Lihuili Hospital) for the hematologic examination.

\section{Disclosure}

The authors report no conflicts of interest for this work.

\section{References}

1. Torre LA, Bray F, Siegel RL, Ferlay J, Lortet-Tieulent J, Jemal A. Global cancer statistics, 2012. CA Cancer J Clin. 2015;65(2):87-108. doi:10.3322/caac. 21262

2. Torre LA, Siegel RL, Ward EM, Jemal A. Global cancer incidence and mortality rates and trends-an update. Cancer Epidemiol Biomarkers Prev. 2016;25(1):16-27. doi:10.1158/1055-9965.EPI-15-0578

3. Wang QL, Xie SH, Wahlin K, Lagergren J. Global time trends in the incidence of esophageal squamous cell carcinoma. Clin Epidemiol. 2018;10:717-728. doi:10.2147/CLEP.S166078

4. Hoeben A, Polak J, Van De Voorde L, Hoebers F, Grabsch HI, de Vos-geelen J. Cervical esophageal cancer: a gap in cancer knowledge. Ann Oncol. 2016;27(9):1664-1674. doi:10.1093/annonc/mdw183

5. Shapiro J, van Lanschot JJB, Hulshof M, et al. Neoadjuvant chemoradiotherapy plus surgery versus surgery alone for oesophageal or junctional cancer (CROSS): long-term results of a randomised controlled trial. Lancet Oncol. 2015;16(9):1090-1098. doi:10.1016/ S1470-2045(15)00040-6

6. Vellayappan BA, Soon YY, Ku GY, Leong CN, Lu JJ, Tey JC. Chemoradiotherapy versus chemoradiotherapy plus surgery for esophageal cancer. Cochrane Database Syst Rev. 2017;8(8):CD010511. doi:10.1002/14651858.CD010511.pub2

7. Cooper JS, Guo MD, Herskovic A, et al. Chemoradiotherapy of locally advanced esophageal cancer: long-term follow-up of a prospective randomized trial (RTOG 85-01). Radiation therapy oncology group. JAMA. 1999;281(17):1623-1627. doi:10.1001/jama. 281.17.1623

8. Bedenne L, Michel P, Bouché O, et al. Chemoradiation followed by surgery compared with chemoradiation alone in squamous cancer of the esophagus: FFCD 9102. J Clin Oncol. 2007;25(10):1160-1168. doi:10.1200/JCO.2005.04.7118

9. Morgan MA, Lewis WG, Casbard A, et al. Stage-for-stage comparison of definitive chemoradiotherapy, surgery alone and neoadjuvant chemotherapy for oesophageal carcinoma. Br J Surg. 2009;96 (11):1300-1307. doi:10.1002/bjs.6705

10. Teoh AY, Chiu PW, Yeung WK, Liu SY, Wong SK, Ng EK. Longterm survival outcomes after definitive chemoradiation versus surgery in patients with resectable squamous carcinoma of the esophagus: results from a randomized controlled trial. Ann Oncol. 2013;24 (1):165-171. doi:10.1093/annonc/mds206

11. Lin SH, Wang L, Myles B, et al. Propensity score-based comparison of long-term outcomes with 3-dimensional conformal radiotherapy vs intensity-modulated radiotherapy for esophageal cancer. Int J Radiat Oncol Biol Phys. 2012;84(5):1078-1085. doi:10.1016/j.ijrobp.2012. 02.015

12. Shi A, Liao Z, Allen PK, et al. Long-term survival and toxicity outcomes of intensity modulated radiation therapy for the treatment of esophageal cancer: a large single-institutional cohort study. $A d v$ Radiat Oncol. 2017;2(3):316-324. doi:10.1016/j.adro.2017.04.002 
13. Higuchi K, Koizumi W, Tanabe S, et al. Current management of esophageal squamous-cell carcinoma in Japan and other countries. Gastrointest Cancer Res. 2009;3(4):153-161.

14. Grimm JC, Valero V, Molena D. Surgical indications and optimization of patients for resectable esophageal malignancies. J Thorac Dis. 2014;6(3):249-257. doi:10.3978/j.issn.2072-1439.2013.11.18

15. Balkwill F, Mantovani A. Inflammation and cancer: back to Virchow? Lancet (London, England). 2001;357(9255):539-545. doi:10.1016/ S0140-6736(00)04046-0

16. Mantovani A, Allavena P, Sica A, Balkwill F. Cancer-related inflammation. Nature. 2008;454(7203):436-444. doi:10.1038/nature 07205

17. Guthrie GJ, Charles KA, Roxburgh CS, Horgan PG, McMillan DC, Clarke SJ. The systemic inflammation-based neutrophil-lymphocyte ratio: experience in patients with cancer. Crit Rev Oncol Hematol. 2013;88(1):218-230. doi:10.1016/j.critrevonc.2013.03.010

18. Stotz M, Gerger A, Eisner F, et al. Increased neutrophil-lymphocyte ratio is a poor prognostic factor in patients with primary operable and inoperable pancreatic cancer. Br J Cancer. 2013;109(2):416-421. doi:10.1038/bjc.2013.332

19. Lindenmann J, Fink-Neuboeck N, Koesslbacher M, et al. The influence of elevated levels of C-reactive protein and hypoalbuminemia on survival in patients with advanced inoperable esophageal cancer undergoing palliative treatment. J Surg Oncol. 2014;110(6):645-650. doi: $10.1002 /$ jso. 23711

20. Pinato DJ, Shiner RJ, Seckl MJ, Stebbing J, Sharma R, Mauri FA. Prognostic performance of inflammation-based prognostic indices in primary operable non-small cell lung cancer. Br J Cancer. 2014;110 (8):1930-1935. doi:10.1038/bjc.2014.145

21. Templeton AJ, Ace O, McNamara MG, et al. Prognostic role of platelet to lymphocyte ratio in solid tumors: a systematic review and meta-analysis. Cancer Epidemiol Biomarkers Prev. 2014;23 (7):1204-1212. doi:10.1158/1055-9965.EPI-14-0146

22. Yodying H, Matsuda A, Miyashita M, et al. Prognostic significance of neutrophil-to-lymphocyte ratio and platelet-to-lymphocyte ratio in oncologic outcomes of esophageal cancer: a systematic review and meta-analysis. Ann Surg Oncol. 2016;23(2):646-654. doi:10.1245/ s10434-015-4869-5

23. Zhou XL, Li YQ, Zhu WG, et al. Neutrophil-to-lymphocyte ratio as a prognostic biomarker for patients with locally advanced esophageal squamous cell carcinoma treated with definitive chemoradiotherapy. Sci Rep. 2017;7(1):42581. doi:10.1038/srep42581

24. Hanahan D, Weinberg RA. Hallmarks of cancer: the next generation. Cell. 2011;144(5):646-674. doi:10.1016/j.cell.2011.02.013

25. Kuper H, Adami HO, Trichopoulos D. Infections as a major preventable cause of human cancer. J Intern Med. 2000;248(3):171-183. doi:10.1046/j.1365-2796.2000.00742.x
26. Diakos CI, Charles KA, McMillan DC, Clarke SJ. Cancer-related inflammation and treatment effectiveness. Lancet Oncol. 2014;15 (11):e493-503. doi:10.1016/S1470-2045(14)70263-3

27. Grivennikov SI, Greten FR, Karin M. Immunity, inflammation, and cancer. Cell. 2010;140(6):883-899. doi:10.1016/j.cell.2010.01.025

28. Bambace NM, Holmes CE. The platelet contribution to cancer progression. J Thromb Haemost. 2011;9(2):237-249. doi:10.1111/ j.1538-7836.2010.04131.x

29. Kang MH, Go SI, Song HN, et al. The prognostic impact of the neutrophil-to-lymphocyte ratio in patients with small-cell lung cancer. Br J Cancer. 2014;111(3):452-460. doi:10.1038/bjc.2014.317

30. Pine JK, Morris E, Hutchins GG, et al. Systemic neutrophil-tolymphocyte ratio in colorectal cancer: the relationship to patient survival, tumour biology and local lymphocytic response to tumour. Br J Cancer. 2015;113(2):204-211. doi:10.1038/bjc.2015.87

31. Cummings M, Merone L, Keeble C, et al. Preoperative neutrophil: lymphocyte and platelet: lymphocyte ratios predict endometrial cancer survival. Br J Cancer. 2015;113(2):311-320. doi:10.1038/bjc.20 15.200

32. Yang $\mathrm{J}, \mathrm{Xu} \mathrm{H}$, Guo X, et al. Pretreatment inflammatory indexes as prognostic predictors for survival in colorectal cancer patients receiving neoadjuvant chemoradiotherapy. Sci Rep. 2018;8(1):3044. doi:10.1038/s41598-018-21093-7

33. Zhang $\mathrm{X}, \mathrm{Hu} \mathrm{D}$, Lin $\mathrm{X}$, et al. Prognostic value of an inflammation-related index in 6865 chinese patients with postoperative digestive tract cancers: the FIESTA study. Front Oncol. 2019;9:427. doi:10.3389/fonc.2019.00427

34. Labelle M, Begum S, Hynes RO. Direct signaling between platelets and cancer cells induces an epithelial-mesenchymal-like transition and promotes metastasis. Cancer Cell. 2011;20(5):576-590. doi:10.1016/j.ccr.2011.09.009

35. Schumacher D, Strilic B, Sivaraj KK, Wettschureck N, Offermanns S. Platelet-derived nucleotides promote tumor-cell transendothelial migration and metastasis via P2Y2 receptor. Cancer Cell. 2013;24(1):130-137. doi:10.1016/j.ccr.2013.05.008

36. Hu B, Yang XR, Xu Y, et al. Systemic immune-inflammation index predicts prognosis of patients after curative resection for hepatocellular carcinoma. Clin Cancer Res. 2014;20(23):6212-6222. doi:10. 1158/1078-0432.CCR-14-0442

37. Ammirante M, Luo JL, Grivennikov S, Nedospasov S, Karin M. B-cell-derived lymphotoxin promotes castration-resistant prostate cancer. Nature. 2010;464(7286):302-305. doi:10.1038/nature08782

38. Fang P, Jiang W, Davuluri R, et al. High lymphocyte count during neoadjuvant chemoradiotherapy is associated with improved pathologic complete response in esophageal cancer. Radiother Oncol. 2018;128(3):584-590. doi:10.1016/j.radonc.2018.02.025
Cancer Management and Research

\section{Publish your work in this journal}

Cancer Management and Research is an international, peer-reviewed open access journal focusing on cancer research and the optimal use of preventative and integrated treatment interventions to achieve improved outcomes, enhanced survival and quality of life for the cancer patient.
The manuscript management system is completely online and includes a very quick and fair peer-review system, which is all easy to use. Visit http://www.dovepress.com/testimonials.php to read real quotes from published authors. 